\title{
Reprocessing and Reuse of Endoscopic Accessories
}

\author{
Vikram Bhatia ${ }^{1}$ Vaishali Bhardwaj ${ }^{2}$ Harsh Vardhan Tevethia ${ }^{1}$ \\ ${ }^{1}$ Department of Hepatology, Institute of Liver and Biliary Sciences \\ (ILBS), New Delhi, India \\ 2 Department of Gastroenterology, PGIMER RML Hospital, New Delhi, \\ India
} Address for correspondence Vikram Bhatia, MD, DM, 169, Vaishali, Pitampura, Delhi 110034, India (e-mail: vikrambhatiadr@gmail.com).

J Digest Endosc 2021;12:214-220.

\begin{abstract} Keywords

- endoscopic accessories

- reprocessing

- sterilization

- biopsy forceps

- papillotomes

- snares

- baskets

Endoscopic accessories are critical devices that breach sterile body sites. They have unique reprocessing difficulties compared with other medical and surgical devices because of their complex structure, narrow lumens, thermolabile construction materials, and application through a semicritical endoscopic device. In addition, there is the possibility of functional derangement of endoscopic accessories with reprocessing, and most are now marketed as single-use devices. While reprocessing of endoscopes has been the subject of numerous societal guidelines, the issue of reprocessing endoscopic accessories and ancillary detachable devices used with the endoscope is seldom addressed. We summarize the existing data on the cleaning and reprocessing of endoscopic accessories.
\end{abstract}

\section{Introduction}

More than 30 years ago, Earle H. Spaulding categorized instruments for patient care as critical, semicritical, and noncritical, according to the degree of infection risk involved with the use of these items. ${ }^{1}$ Critical items should be purchased sterile or be sterilized before patient use. Examples of critical category devices include surgical instruments, cardiac and urinary catheters, implants, and ultrasound probes used in sterile body cavities. Endoscopic accessories (EAs) are also considered critical devices, as they may break mucus membranes or may be directly introduced into normally sterile areas of the body or bloodstream. ${ }^{2}$ EAs must be sterile at the point of use.

Most EAs are now marketed as single-use devices (SUDs). Reuse of any SUD involves regulatory, ethical, medical, legal, and economic issues. ${ }^{3}$ There are two potential risks associated with the reuse of SUDs: an increased risk of infection and inadequate device performance after reprocessing. The public and press have expressed increasing concern regarding the risk of infection and injury when reusing medical devices intended for single use. The downsides of exclusive use of SUDs in endoscopy are the increase in biowaste generated and the increased procedural costs.

\section{What Are the Challenges with Reprocessing of Endoscopic Accessories?}

Surgical instruments used in gynecological, general surgical, orthopaedic, and ear-nose-throat operations usually have contamination with relatively low bioburden after patient use. ${ }^{4,5}$ Nyström reported that $91 \%$ of surgical instruments were contaminated with $<10^{3}$ organisms after patient use. ${ }^{6}$ There are no data on the bioburden and microbial contamination levels on EAs after patient use. Unlike most surgical instruments, EAs have complex internal structures, with narrow lumens and thin joints and crevices, and are difficult to disassemble. Hence, EAs present unique challenges in
DOI https://doi.org/ 10.1055/s-0041-1741077. ISSN 0976-5042. (c) 2022. Society of Gastrointestinal Endoscopy of India. All rights reserved.

This is an open access article published by Thieme under the terms of the Creative Commons Attribution-NonDerivative-NonCommercial-License, permitting copying and reproduction so long as the original work is given appropriate credit. Contents may not be used for commercial purposes, or adapted, remixed, transformed or built upon. (https://creativecommons.org/ licenses/by-nc-nd/4.0/)

Thieme Medical and Scientific Publishers Pvt. Ltd., A-12, 2nd Floor, Sector 2, Noida-201301 UP, India 
their reprocessing. We will discuss the reprocessing steps of EAs later in this review.

A practical problem with implementing reprocessing policies based on the Spaulding scheme is the use of EAs categorized as critical devices in conjunction with endoscopes that are categorized as semicritical devices. ${ }^{7,8}$ This situation is different from surgical instruments, which are usually used in sterile operating fields. For example, is sterility of a biopsy forceps maintained after passage through the contaminated accessory channel of an endoscope? Can lesser standards such as disinfection be implemented for EAs? EAs are often passed into or through heavily contaminated body cavities such as the oral cavity or the colon. Endoscopy guidelines should consider EAs as a unit with the endoscope, along with the implemented endoscopic procedure.

\section{Which Endoscopic Accessories Are Reusable?}

The basic prerequisites for any medical device or accessory to be reusable include the following:

- The ability to disassemble (and reassemble) the device without impairing its functionality.

- The lumens of the device must be flushable, i.e., open at both ends.

- The device components must be tolerant to the sterilization processes.

Only a few EAs from Olympus India are marketed as reusable devices in this country. These include a reusable snare and snare handle, reusable clip applicator, handle of mechanical lithotriptor, hot biopsy forceps, a model of reusable forceps, and rat-tooth and alligator-jaw grasping forceps.

\section{Which Endoscopic Accessories Are Single- Use Devices?}

Most EAs in the Indian and international market are SUDs. Cook Medical and Boston Scientific, India, only market single-use endoscope devices in India. Examples of singleuse EAs include all guidewires, sphincterotomes, stone extraction baskets (including mechanical lithotripsy baskets), stone extraction balloons, dilatation balloons, tapered dilatation bougies, hemostatic forceps (e.g., Coagrasper; Olympus Co. Ltd., Tokyo, Japan), and endoscopic ultrasound (EUS) balloons. Most electrosurgery devices such as needle knives, cystotomes, sphincterotomes, bipolar probes, and argon plasma coagulation probes are also SUDs.

SUDs are instruments designed for one-time use, on one patient, and during a single procedure. This implies that single-use EAs cannot be reused during a repeat procedure even on the same patient. Single-use EAs cannot be adequately reprocessed, as their lumens are usually closed at one end, allowing microorganisms and debris to enter during endoscopy but complicating the cleaning and sterilization processes intended to extract these materials.

\section{Cost of Endoscopic Accessories and Discrepancy with Reimbursement}

The procedure costs significantly increase with the exclusive use of SUDs. This is of particular importance in India where most patients are self-payers, and insurance reimbursements are capped. Even the governmental agencies do not acknowledge the market cost of basic accessories when deciding procedural reimbursements. Some examples of such economic ambiguities are displayed in - Table 1.

The dual problems of nonavailability of reusable EAs combined with high costs of single-use accessories that are noncommensurate with the procedural reimbursements perpetuate the ignominious practice of reuse of SUDs, often without patient disclosure. There are sparse objective data about real-world accessory reprocessing practices in the Asia-Pacific. In a survey reported in 2000 , over $95 \%$ of respondents reused disposable accessories after what they considered as adequate "sterilization." Only one-quarter used autoclaving or ethylene oxide (ETO) sterilization, and $43 \%$ relied on glutaraldehyde. ${ }^{9}$ The situation has not changed

Table 1 Examples of some common endoscopic procedures with the approximate cost of required single-use devices, and the sanctioned reimbursements for the same

\begin{tabular}{|l|l|l|l|l|}
\hline & Procedure examples & Accessories required & $\begin{array}{l}\text { Estimated } \\
\text { approximate } \\
\text { cost of SUDs } \\
\text { accessories }^{\text {a }}\end{array}$ & $\begin{array}{l}\text { CGHS-approved rates } \\
\text { for Delhi/NCR }\end{array}$ \\
\hline 1 & Endoscopic biopsy & 1,500 & 397 \\
\hline 2 & Endoscopic dilatation with SGD & SGD $\times 3$ & 60,000 & 1,984 \\
\hline 3 & Polypectomy & Snare & 2,000 & - \\
\hline 4 & ERCP with stone extraction & $\begin{array}{l}\text { Sphincterotome }+ \text { hybrid } \\
\text { wire }+ \text { balloon }\end{array}$ & 26,000 & 2,777 \\
\hline 5 & Mechanical lithotripsy & $\begin{array}{l}\text { Sphincterotome }+ \text { hybrid } \\
\text { wire +lithotriptor basket + balloon }\end{array}$ & 49,000 & 9,200 \\
\hline
\end{tabular}

Abbreviations: CGHS, Central Government Health Scheme (of India); ERCP, endoscopic retrograde cholangiopancreatography; NCR, national capital region; SGD, Savary-Gilliard dilator; SUD, single-use devices.

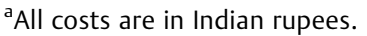

${ }^{\mathrm{b}}$ Rates are for NABH (National Accreditation Board for Hospitals and Healthcare Providers)-accredited hospitals. 
over the last two decades. In a recent online survey conducted by the authors (unpublished data), $100 \%$ of respondents from India accepted reusing single-use EAs; majority did not inform the patients.

\section{Legal Liabilities and Societal Guidelines}

There are no comprehensive guidelines from major endoscopy or gastroenterology societies on the reuse of single-use EAs and the reprocessing of reusable EAs. In a guidance document issued in 2000, the Food and Drug Administration (FDA) stated that hospitals or third-party reprocessors will be considered as "manufacturers" and regulated in the same manner. A reused SUD will have to comply with the same regulatory requirements of the device as when it was originally manufactured. ${ }^{10}$

In a 2016 document ${ }^{11}$ dealing with decontamination and reprocessing of medical devices, the World Health Organization (WHO) recommended the following:

- Organizations must have written policies on SUDs.

- Critical and semicritical medical devices labeled as single use should not be reprocessed unless a licensed reprocessor does the reprocessing.

- Devices with small lumens such as catheters, drains, and fine cannulas should not be reprocessed and reused.

- Reprocessing may alter device characteristics, and performance may be compromised.

These WHO guidelines practically forbid the reuse of any SUD during endoscopic procedures and highlight the need for an organizational policy to be in place instead of individual user discretion.

Joint Commission International (JCI) Accreditation Standards document 2017 (6th edition) ${ }^{12}$ includes specific requirements when SUDs are reused:
- If SUDs are reused in the hospital, a hospital policy must be created that guides such reuse.

- The hospital must identify which SUD it will allow to be reused.

- There should be a process for determining when a SUD is no longer safe or suitable for reuse.

- Hospitals should have and follow a clear protocol for cleaning, disinfecting, and sterilizing each SUD; ideally, the protocol should be device-specific.

- There should be a protocol to identify patients on whom reusable medical devices were used, for tracking.

- When national laws or regulations exist, the hospital policy must be consistent with these, as well as professional standards.

JCI recently issued an updated document in 2021 (7th edition), which continues to endorse the above-mentioned recommendations. The JCI guidelines maintain that the hospital should identify and implement a process for managing the reuse of SUDs, consistent with regional and local laws and regulations. It also requires that the hospital should implement a process for managing expired supplies. The JCI guidelines are pragmatic and are the only reference for the endoscopist who acknowledges that in third-world countries SUDs may be reprocessed and reused.

\section{Steps for Reprocessing Reusable Endoscopic Accessories}

The steps detailed in this section deal with reprocessing EAs that are labeled as reusable. It should be noted that singleuse accessories cannot be adequately cleaned and sterilized (-Fig. 1).
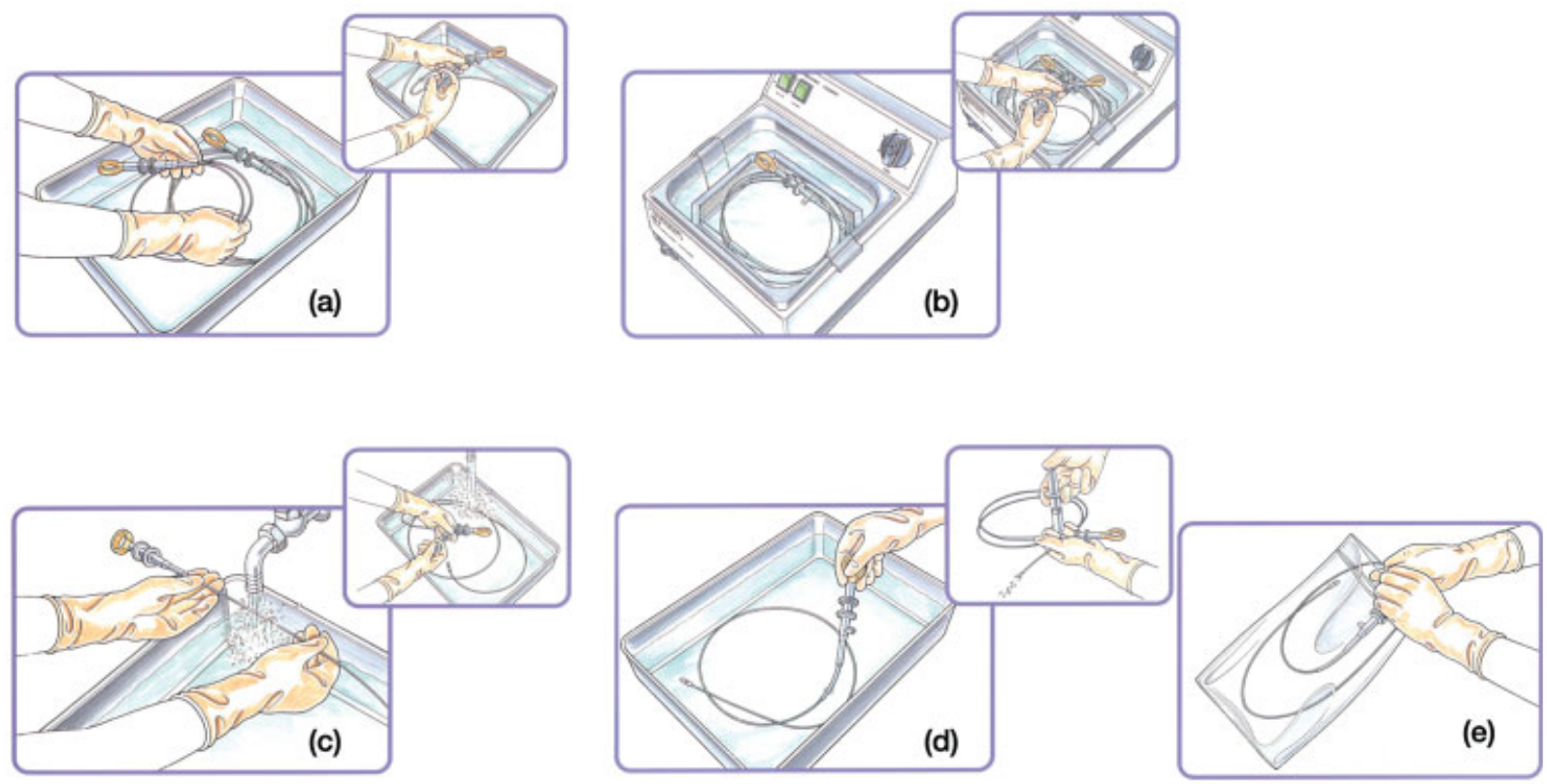

Fig. 1 Steps for reprocessing reusable endoscopic accessories: (a) manual cleaning and immersion in detergent; (b) ultrasonic cleaning; (c) rinsing and flushing with water; (d) lubrication; and (e) sterilization (autoclaving or ethylene oxide sterilization). 


\section{Step 1: Cleaning and Immersion in Detergent}

After an EA has been used, it should be mechanically cleaned as soon as possible to prevent drying of debris. Precleaning of the EA in the procedure room or at the point of use may be needed for items that are heavily soiled with feces, sputum, blood, or other biomaterials. Once organic and inorganic debris has dried inside the device, it will be very difficult clean mechanically. Retained debris leads to formation of biofilms inside the device; bacteria within biofilms are up to 1,000 times more resistant to antimicrobials than are the same bacteria in suspension. ${ }^{13}$ In an experimental study, it was found that if reprocessing of sphincterotomes was delayed for more than 24 hours, flushing-cleaning was no longer effective, and ETO sterilization failure was detected when devices were held for 7 days. ${ }^{14}$ Meticulous cleaning is essential before high-level disinfection (HLD) or sterilization, because inorganic and organic residues interfere with the effectiveness of these processes. ${ }^{15,16}$

The steps for manual cleaning of EAs are as follows:

- Immerse in neutral, low-foaming detergent immediately after use.

- Dismantle as far as possible.

- Clean all surfaces using disposable cloth/sponge/brushes.

- Immersion time: 5 to 30 minutes.

- Flush any port with 10-mL detergent.

\section{Step 2: Ultrasonic Cleaning}

Manual cleaning of complex and spiral-based structures of many endoscopic devices may be inadequate. Ultrasonic (US) cleaning removes soil by cavitation and implosion (the rapid formation and collapse of bubbles), which occurs in the immersing solution, removing debris from corners and crevices of the EAs that may be inaccessible to manual cleaning. US cleaning is considered an essential prerequisite if an EA is to be sterilized by autoclaving, as the high temperature reached during processing will cause any debris remaining on or inside the device to be solidified and fixed.

Some washer-disinfectors for flexible endoscopes offer special reprocessing programs for heat-stable accessories.

The EAs are immersed in detergent in the tray of the US cleaner. The usual cleaning cycle duration for US cleaning is around 30 minutes. The tray of the US cleaner should not be overloaded, to avoid US "shadows" or dead space. US cleaning devices offer a frequency range of over $30 \mathrm{kHz}(38-47 \mathrm{kHz})$ and a maximum operating temperature of $40^{\circ} \mathrm{C}$.

\section{Step 3: Rinsing}

After removal from the US cleaner tray, the EAs are thoroughly rinsed and flush with clean water to remove any residual detergent.

\section{Step 4: Lubrication}

Mineral oil lubricants that are nonsticky, nontoxic, siliconefree, and water soluble are commercially available. These lubricants can withstand the high temperatures of autoclaving without becoming gummy. These rinse lubricants for EAs should be anticorrosive and steam and ETO permeable.
The steps of lubrication of accessories with movable joints are as follows:

- Insert insertion portion in lubricant for few seconds.

- Inject lubricant via the flushing port.

- Then inject air to flush excess.

- Wipe and air dry.

\section{Step 5: Sterilization or High-Level Disinfection}

Sterilization of endoscopic devices can be achieved by autoclaving or gas sterilization by ETO. Autoclaving is the least expensive and safest method of sterilization. EAs that are autoclavable may carry a green label or have "autoclavable" written on the device itself. However, ETO sterilization may be the optimal sterilization technique for most EAs, as they are usually made of heat- or moisture-sensitive materials. ETO sterilization is a low-temperature process (37-63 C). ETO sterilization remains effective for lumens as small as $1 \mathrm{~mm}$, in the absence of salt or serum. The accessory is coiled and inserted into a suitable sterile package and sealed, and the ETO gas will permeate this sealed packaging. For ETO sterilization, complete drying before and adequate aeration for $>24$ hours after are needed. ETO gas is a biohazard and a carcinogen.

If adequate manual cleaning is achieved, including US cleaning, a 10 -minute soak in $2 \%$ glutaraldehyde may be used for HLD of EAs. It should be noted that liquid disinfectants usually cannot achieve direct contact with all surfaces of an accessory. In some countries, such as Germany, disinfection is recommended as an additional step after US cleaning before sterilization.

In the above-mentioned online survey of gastroenterologists from India, conducted by the authors (unpublished data), only 22.2 and $53.3 \%$ of the respondents used detergents and disinfectant solution, respectively, for reprocessing of EAs. Only $11 \%$ used US cleaning, $62 \%$ used ETO sterilization, and $2.2 \%$ used autoclaving.

\section{Reprocessing of Specific Endoscopic
Accessories}

\section{Biopsy Forceps}

There are usually four layers of construction of a biopsy forceps; lumen of a single-use biopsy forceps is open only at the distal end and, hence, flushing is not a viable option. Attempts to clean the biopsy forceps by flushing and aspirating cleaning fluid through the single opening have been shown to spread contaminants further throughout the instrument. Hence, single-use biopsy forceps cannot be reprocessed for reuse and should be discarded after a single procedure in one patient.

The number of times a reusable forceps can be reused ranges from 10 to 100 . Reprocessing of reusable biopsy forceps includes the following steps: soaking, brushing and cleaning, rinsing, US cleaning, drying, lubrication, repackaging, and sterilization. Reusable biopsy forceps are heat-stable and can be cleaned with a US cleaner and steam-sterilized. Sterilization with ETO gas may be inadequate because of the 
Table 2 Studies of reprocessing of single-use and reusable biopsy forceps

\begin{tabular}{|c|c|c|}
\hline & Accessories studied & Key study message \\
\hline Hambrick $^{17}$ & Single-use biopsy forceps & $\begin{array}{l}\text { Unable to adequately sterilize despite reprocessing } \\
\text { by third party }\end{array}$ \\
\hline Heeg et al ${ }^{18}$ & Single-use and reusable biopsy forceps & $\begin{array}{l}\text { Contaminated with Tc99-labeled blood; reusable } \\
\text { devices disinfected but not single-use devices }\end{array}$ \\
\hline Jung et al $^{19}$ & Reusable biopsy forceps, without spike & Could be adequately sterilized after 20 uses \\
\hline Kozarek et al ${ }^{20}$ & Reusable biopsy forceps & $\begin{array}{l}\text { Can be sterilized and used a mean of } 91 \text { times; no } \\
\text { mechanical problems }\end{array}$ \\
\hline Rizzo et $\mathrm{al}^{21}$ & Reusable vs. single-use biopsy forceps & $\begin{array}{l}\text { Single-use forceps rated superior by users; residual } \\
\text { debris on reusable forceps despite cleaning }\end{array}$ \\
\hline Yang et $a l^{22}$ & Single-use vs. reusable biopsy forceps & $\begin{array}{l}\text { Reusable forceps cost-effective if used > } 20 \text { times; } \\
\text { performance diminishes with use }\end{array}$ \\
\hline Yoon et $\mathrm{al}^{23}$ & Reusable biopsy forceps after 20 uses & $\begin{array}{l}\text { Abundant debris on EM after processing; autoclav- } \\
\text { ing may be more effective than ETO }\end{array}$ \\
\hline
\end{tabular}

Abbreviations: EM, electron microscopy; ETO, ethylene oxide.

complicated structure of the forceps that may interfere with gas sterilization.

Studies of reprocessing of biopsy forceps are summarized in - Table 2.

\section{Papillotomes}

The cutting portion of the cautery wire emerges from a separate and nonirrigatable catheter port at the papillotome tip. Note that all papillotomes now available are single use and cannot be adequately cleaned and sterilized. The studies of reprocessing of papillotomes are summarized in - Table 3 .

\section{Baskets and Snares}

Stone extraction baskets are reusable for 10 to 13 times. They are marketed as SUDs, and existing studies are unclear if these devices can be adequately sterilized. ${ }^{18,25}$ There is a single study reporting that snares could not be adequately sterilized. $^{17}$

The studies detailing reprocessing of baskets and snares are summarized in - Table 4.

\section{Endoscopic Ultrasound Needles}

All EUS needles are SUDs as they breach the gastrointestinal wall and contact patient's blood and secretions. These needles are complex devices and cannot be adequately cleaned. Bhatia et al used Adenosine triphosphate (ATP) bioluminescence technique to show significant residual bioburden on the surface and inside the fine needle aspiration devices after standardized reprocessing. ${ }^{27}$ Hence, EUS needles should never be reused.

\section{Accessories Used with the Endoscope}

These can be divided into two categories:

- Those accessories that are manually cleaned and disinfected with the endoscope itself. These include endoscope cleaning and flushing accessories such as channel plug, injection tube, and auxiliary water tube.

- Those accessories that are not cleaned or disinfected with the endoscope and must be reprocessed separately. This category includes the biopsy valves, air-water (AW) valve,

Table 3 Studies of reprocessing of single-use and reusable papillotomes

\begin{tabular}{|c|c|c|}
\hline & Accessories studied & Key study message \\
\hline Cohen et $\mathrm{al}^{24}$ & 25 papillotomes & Papillotomes reusable for 8 (median) times \\
\hline Heeg et al $^{18}$ & Single-use and reusable papillotomes & $\begin{array}{l}\text { Contaminated with Tc99-labeled blood; reusable } \\
\text { devices disinfected but not single-use devices }\end{array}$ \\
\hline Kozarek et al ${ }^{20}$ & Single- and double-lumen papillotomes & $\begin{array}{l}\text { Double channel more difficult to clean than single } \\
\text { channel; functional integrity for 5-10 uses; manual } \\
\text { cleaning followed by ETO. Sterilization effective }\end{array}$ \\
\hline Lee et $\mathrm{al}^{26}$ & Reusable double-channel papillotomes & $\begin{array}{l}\text { Effectively sterilized with ETO; loss of function } \\
\text { after mean } 3.1 \text { uses }\end{array}$ \\
\hline Prat et $\mathrm{al}^{25}$ & $\begin{array}{l}\text { Reusable single-lumen and } \\
\text { double-lumen papillotomes }\end{array}$ & $\begin{array}{l}\text { Reuse safe after steam sterilization; median num- } \\
\text { ber of reuses } 8-12 \text { for papillotomes }\end{array}$ \\
\hline
\end{tabular}


Table 4 Studies of reprocessing of stone extraction baskets and snares

\begin{tabular}{|c|c|c|}
\hline & Accessories studied & Key study message \\
\hline Cohen et $\mathrm{al}^{24}$ & 15 baskets & Baskets reusable for 13 (median) times \\
\hline Heeg et al ${ }^{18}$ & $\begin{array}{l}\text { Single-use and } \\
\text { reusable baskets }\end{array}$ & $\begin{array}{l}\text { Contaminated with Tc99-labeled blood; reusable devices } \\
\text { disinfected but not single-use devices }\end{array}$ \\
\hline Prat et a ${ }^{25}$ & Baskets & $\begin{array}{l}\text { Reuse safe after steam sterilization; median number of } \\
\text { reuses } 10 \text { for baskets }\end{array}$ \\
\hline Hambrick $^{17}$ & Oval jumbo snares & $\begin{array}{l}\text { Unable to adequately sterilize despite reprocessing by third } \\
\text { party }\end{array}$ \\
\hline
\end{tabular}

suction valve, AW channel-cleaning adapter, channelcleaning brush, channel opening-cleaning brush, suction-cleaning adapter, and the water bottles. These accessories may or may not be compatible with the Automated endoscope reprocessor, and thus must be disinfected manually separately from the endoscope.

Reprocessing of the accessories used with the endoscope involves the following steps:

- Manually clean all accessories in detergent solution. For suction valves, AW valves, and biopsy valves, use a channel-cleaning brush; depress and release pistons of valves in the detergent solution; use syringe to flush all openings of accessories with the detergent.

- If there is any remnant debris, US cleaner may be used.

- Manual cleaning is followed by sequence of rinsing, disinfectant soak, rinsing, and then alcohol flush.

- All these accessories can be autoclaved.

The water bottle used with the endoscopic procedures is often ignored as a potential source of contamination. Only sterile water must be used in the water bottle, and the water bottle must be reprocessed (cleaned and disinfected or sterilized) at least once daily. For reprocessing, the water bottle must be disassembled completely, followed by manual cleaning in detergent. The external surfaces are cleaned, followed by flushing through the cap of the lid assembly with a $30-\mathrm{mL}$ syringe four times. The water bottle is then disinfected or sterilized. The endoscope water bottle is not compatible with ETO sterilization. Endoscope water bottles should be discarded after 1 year of use or 200 cycles of reprocessing.

\section{Storage of Reprocessed Accessories}

Following the sterilization process, medical and surgical devices must be handled using aseptic technique to prevent recontamination. The same principles laid down for sterilized surgical devices may be used for storage of reprocessed EAs, although there are no systematic data directly dealing with endoscopic devices. The reprocessed accessories should be stored far enough from the floor (8-10 inches), the ceiling ( 5 inches), and the outside walls ( 2 inches) to allow for adequate air circulation and ease of cleaning the storage site. Storage sites should not be under sinks or in other locations where they can become wet. Closed or covered cabinets are ideal but open shelving may be used for storage of EAs. ${ }^{28,29}$

\section{Summary}

Majority of EAs are SUDs, which cannot be adequately reprocessed. Market cost of single-use EAs is unrealistic compared with reimbursement and procedural costs. When SUDs are reused, there should be a hospital policy that guides such reuse. This policy should be consistent with national laws and regulations and professional standards, and patient consent may be considered. Accessories used with the endoscope and endoscope-cleaning accessories should themselves be reprocessed. Using unclean accessories with an adequately reprocessed endoscope is illogical.

\section{Authors' Contribution}

Vikram Bhatia wrote the manuscript. Vaishali Bhardwaj and Harsh Vardhan Tevethia reviewed and contributed to the manuscript.

Funding

None.

Conflict of Interest

None declared.

\section{References}

1 Spaulding EH. Chemical disinfection of medical and surgical materials. In: Lawrence C, Block SS, eds. Disinfection, Sterilization, and Preservation. Philadelphia, PA: Lea \& Febiger; 1968: 517-531

2 Beilenhoff $\mathrm{U}$, Biering $\mathrm{H}$, Blum $\mathrm{R}$, et al. Reprocessing of flexible endoscopes and endoscopic accessories used in gastrointestinal endoscopy: Position Statement of the European Society of Gastrointestinal Endoscopy (ESGE) and European Society of Gastroenterology Nurses and Associates (ESGENA) - Update 2018. Endoscopy 2018;50(12):1205-1234

3 Greene VW. Reuse of disposable medical devices: historical and current aspects. Infect Control 1986;7(10):508-513

4 Chan-Myers H, McAlister D, Antonoplos P. Natural bioburden levels detected on rigid lumened medical devices before and after cleaning. Am J Infect Control 1997;25(06):471-476

5 Rutala WA, Gergen MF, Jones JF, Weber DJ. Levels of microbial contamination on surgical instruments. Am J Infect Control 1998; 26(02):143-145 
6 Nyström B. Disinfection of surgical instruments. J Hosp Infect 1981;2(04):363-368

7 Lee RM, Kozarek RA, Sumida SE, Raltz SL. Risk of contamination of sterile biopsy forceps in disinfected endoscopes. Gastrointest Endosc 1998;47(05):377-381

8 Kinney TP, Kozarek RA, Raltz S, Attia F. Contamination of singleuse biopsy forceps: a prospective in vitro analysis. Gastrointest Endosc 2002;56(02):209-212

9 Ahuja V, Tandon RK. Survey of gastrointestinal endoscope disinfection and accessory reprocessing practices in the Asia-Pacific region. J Gastroenterol Hepatol 2000;15(Suppl):G78-G81

10 Food and Drug Administration. Enforcement Priorities for SingleUse Devices Reprocessed by Third Parties and Hospitals. Rockville, MD2000

11 World Health Organization. Decontamination and reprocessing of medical devices for health-care facilities. Accessed August 30 , 2021 at:http://apps.who.int/iris/bitstream/handle/10665/250232/ 9789241549851-eng.pdf

12 https://store.jointcommissioninternational.org/assets/3/7/jci_2018_ publications_brochure_final_11.2017.pdf. Accessed August 30, 2021

13 Vickery K, Pajkos A, Cossart Y. Removal of biofilm from endoscopes: evaluation of detergent efficiency. Am J Infect Control 2004;32(03):170-176

14 Alfa MJ, Nemes R. Inadequacy of manual cleaning for reprocessing single-use, triple-lumen sphinctertomes: simulated-use testing comparing manual with automated cleaning methods. Am J Infect Control 2003;31(04):193-207

15 Abbott CF, Cockton J, Jones W. Resistance of crystalline substances to gas sterilisation. J Pharm Pharmacol 1956;8(10):709-720

16 Jacobs P. Cleaning: principles, methods and benefits. In: Rutala WA, ed. Disinfection, sterilization, and antisepsis in healthcare. Champlain, NY: Polyscience Publications; 1998:165-181

17 Hambrick D III. Reprocessing of single-use endoscopic biopsy forceps and snares. One hospital's study. Gastroenterol Nurs 2001;24(03):112-115

18 Heeg P, Roth K, Reichl R, Cogdill CP, Bond WW. Decontaminated single-use devices: an oxymoron that may be placing patients at risk for cross-contamination. Infect Control Hosp Epidemiol 2001;22(09):542-549
19 Jung M, Beilenhoff U, Pietsch M, Kraft B, Rippin G. Standardized reprocessing of reusable colonoscopy biopsy forceps is effective: results of a German multicenter study. Endoscopy 2003;35(03): 197-202

20 Kozarek RA, Attia FM, Sumida SE, et al. Reusable biopsy forceps: a prospective evaluation of cleaning, function, adequacy of tissue specimen, and durability. Gastrointest Endosc 2001;53(07): 747-750

21 Rizzo J, Bernstein D, Gress F. A performance, safety and cost comparison of reusable and disposable endoscopic biopsy forceps: a prospective, randomized trial. Gastrointest Endosc 2000; 51(03):257-261

22 Yang R, Ng S, Nichol M, Laine L. A cost and performance evaluation of disposable and reusable biopsy forceps in GI endoscopy. Gastrointest Endosc 2000;51(03):266-270

23 Yoon JH, Yoon BC, Lee HL, et al. Comparison of sterilization of reusable endoscopic biopsy forceps by autoclaving and ethylene oxide gas. Dig Dis Sci 2012;57(02):405-412

24 Cohen J, Haber GB, Kortan P, et al. A prospective study of the repeated use of sterilized papillotomes and retrieval baskets for ERCP: quality and cost analysis. Gastrointest Endosc 1997;45(02): 122-127

25 Prat F, Spieler JF, Paci S, et al. Reliability, cost-effectiveness, and safety of reuse of ancillary devices for ERCP. Gastrointest Endosc 2004;60(02):246-252

26 Lee RM, Vida F, Kozarek RA, et al. In vitro and in vivo evaluation of a reusable double-channel sphincterotome. Gastrointest Endosc 1999;49(4 Pt 1):477-482

27 Bhatia V, Gupta A, Sharma S, et al. Residual contamination and bioburden after reprocessing of single-use endoscopic ultrasound needles: an ex vivo study. Dig Endosc 2017;29(02): 175-181

28 Centers for Disease Control and Prevention. Sterilizing practices: guideline for disinfection and sterilization in healthcare facilities. Accessed August 29, 2021 at: https://www.cdc.gov/ infectioncontrol/guidelines/disinfection/sterilization/sterilizing-practices.html

29 Mayworm D. Sterile shelf life and expiration dating. J Hosp Supply Process Distrib 1984;2(06):32-35 